\title{
Diálogos sobre educação ambiental com escolares: um enfoque na educação ambiental crítica
}

\author{
Dialogues on environmental education with schools: a focus on critical environmental \\ educationtítulo
}

Diálogos sobre educación ambiental con las escuelas: un enfoque en la educación ambiental crítica

Recebido: 04/03/2021 | Revisado: 11/03/2021 | Aceito: 11/03/2021 | Publicado: 19/03/2021

Dieison Prestes da Silveira

ORCID: https://orcid.org/0000-0002-8446-4157 Universidade Federal do Paraná, Brasil

E-mail: dieisonprestes@gmail.com

Leonir Lorenzetti

ORCID: https://orcid.org/0000-0002-0208-2965 Universidade Federal do Paraná, Brasil E-mail: leonirlorenzetti22@gmail.com

Denise da Costa Dias Scheffer

ORCID: https://orcid.org/0000-0002-1755-542X Universidade de Cruz Alta, Brasil E-mail: xxxxx@xxxx.xxx.br

Diego Pascoal Golle

ORCID: https://orcid.org/0000-0002-5264-8007 Universidade de Cruz Alta, Brasil E-mail: dgolle@unicruz.edu.br

\begin{abstract}
Resumo
A educação ambiental se apresenta como uma importante forma de intervenção social, buscando um diálogo constante entre sociedade, meio ambiente, cultura, política e economia, auxiliando no desenvolvimento de um pensar crítico e reflexivo dos sujeitos, para as (con)vivências sociais. Partindo da necessidade da abordagem de uma educação ambiental crítica, este artigo busca analisar e discutir um momento dialógico com alunos do sexto ano de uma escola estadual de um município da região noroeste do estado do Rio Grande do Sul, evidenciando a importância das trocas de saberes, vivências e experiências, com vistas a transformar o modo de agir e pensar na sociedade. A metodologia baseia-se numa abordagem qualitativa, por meio de um estudo de caso, cuja a análise dos dados pautou-se na Análise Textual Discursiva. Durante a atividade dialógica, o professor-mediador proferiu diversos questionamentos aos alunos, os quais responderam conforme os seus conhecimentos. Foi possível perceber com as respostas dos alunos uma abordagem conservadora de educação ambiental, relacionando meio ambiente aos rios, florestas e animais. Por meio desta atividade, observa-se a importância do professor no contexto escolar, visando (des)construir conceitos e permitir um (re)pensar nas questões emergentes que estão presentes na contemporaneidade.
\end{abstract}

Palavras-chave: Ensino; Sociedade; Meio ambiente; Alunos.

\begin{abstract}
Environmental education presents itself as an important form of social intervention, seeking a constant dialogue among society, environment, culture, politics and economics, helping in the development of a critical and reflective thinking of the subjects, for the social (con) experiences. Based on the need for a critical environmental education approach, this article seeks to analyze and discuss a dialogical moment with sixth year students from a state school in a municipality in the northwest region of the state of Rio Grande do Sul, highlighting the importance of knowledge exchanges and experiences, with a view to transforming the way of acting and thinking in society. The methodology is based on a qualitative approach, through a case study, whose data analysis was based on Textual Discursive Analysis. During the dialogic activity, the teacher-mediator asked several questions to the students, who answered according to their knowledge. It was possible to perceive with the students' responses a conservative approach to environmental education, relating the environment to rivers, forests and animals. Through this activity, the importance of the teacher in the school context is observed, aiming at (de) constructing concepts and allowing a (re) thinking about the emerging issues that are present in contemporary times.
\end{abstract}

Keywords: Teaching; Society; Environment; Students. 


\begin{abstract}
Resumen
La educación ambiental se presenta como una forma importante de intervención social, buscando un diálogo constante entre la sociedad, el medio ambiente, la cultura, la política y la economía, ayudando en el desarrollo de un pensamiento crítico y reflexivo de los sujetos, para las (con) experiencias sociales. A partir de la necesidad de un enfoque crítico de educación ambiental, este artículo busca analizar y discutir un momento de diálogo con estudiantes de sexto año de una escuela estatal de un municipio de la región noroeste del estado de Rio Grande do Sul, destacando la importancia del conocimiento. intercambios, vivencias y vivencias, con miras a transformar la forma de actuar y pensar en la sociedad. La metodología se basa en un enfoque cualitativo, a través de un estudio de caso, cuyo análisis de datos se basó en el Análisis Textual Discursivo. Durante la actividad dialógica, el docente-mediador hizo varias preguntas a los estudiantes, quienes respondieron de acuerdo a sus conocimientos. Se pudo percibir con las respuestas de los estudiantes un enfoque conservador de la educación ambiental, relacionando el medio ambiente con ríos, bosques y animales. A través de esta actividad se observa la importancia del docente en el contexto escolar, con el objetivo de (des) construir conceptos y permitir un (re) pensar sobre los temas emergentes que están presentes en la época contemporánea.ncluir o resumo em espanhol.
\end{abstract}

Palabras clave: Enseñanza; Sociedad; Medio ambiente; Estudiantes.

\title{
1. Introduçãa
}

A educação ambiental, sendo um processo de construção de conhecimentos, permite transformações nos indivíduos, em seu modo de pensar e agir, culminando num debate emergente nas questões sociais, culturais, econômicas, políticas e educacionais. Quando se problematiza a educação ambiental, cria-se condições para formar sujeitos autônomos, críticos e reflexivos, que saibam atuar de forma ativa na sociedade, debatendo temáticas emergentes e refletindo sobre as ações antrópicas no ecossistema (Carvalho, 2012).

Silveira e Lorenzetti (2021) destacam que na contemporaneidade deve-se haver constantes diálogos, objetivando a construção de novos saberes que podem resultar em conhecimentos. A educação ambiental crítica visa a articulação de saberes sociais, culturais, políticos, ambientais, econômico, os quais permitem a transformação do modo de agir e pensar dos sujeitos. É neste contexto que ocorre o desenvolvimento da criticidade e da autonomia, refletindo diretamente na sociedade.

A educação ambiental precisa ser vista como uma forma de intervenção social, possibilitando um debate epistêmico e analítico entre os mais variados saberes, instigando a compreensão da relevância do diálogo e das suas múltiplas interações, entrelaçando vivências e experiências. Da mesma forma, a discussão envolvendo a educação ambiental precisa libertar os sujeitos das ideias hegemônicas, mitigando casos de alienação ideológica, favorecendo assim um processo libertador e emancipatório para as (con)vivências sociais (Silveira \& Lorenzetti, 2021).

Nos espaços educacionais a educação ambiental precisa ser abordada com ênfase, visando constantes problematizações acerca do meio ambiente e de suas múltiplas interações. O professor, sendo um mediador do conhecimento, deve instigar o diálogo e promover atividades que vão além de uma educação ambiental conservadora, baseada nos processos de reciclagem, coleta de materiais e abordagem de conhecimentos descontextualizados. Deve-se haver intensos debates e diálogos entre professores e alunos, visando a sensibilização ambiental. Da mesma forma, no ambiente escolar a educação ambiental precisa ser abordada de forma interdisciplinar, contribuindo com a valorização da pluralidade de saberes, oriundos dos diversos espaços e realidades dos alunos.

Em se tratando de um debate envolvendo a educação ambiental no espaço escolar, há de se considerar a necessidade da contextualização e correlação com a comunidade em que os sujeitos estão inseridos, haja vista que a abordagem da educação ambiental precisa emergir da realidade de cada indivíduo, para assim, contemplar outros espaços. Neste sentido, deve-se debater temáticas que estão presentes no dia a dia dos alunos, objetivando a socialização de vivências e experiências, com vistas a um (re)pensar nas problemáticas emergentes, como por exemplo, as desigualdades sociais, a saúde, a pobreza, os conflitos sociais e tantas outras situações desafiadoras que contemplam o espaço educacional.

A educação ambiental, pelo viés crítico, permite um olhar mais profundo de meio ambiente, pois ela permite discussões sociais, culturais, locais, ambientais, entrelaçando conhecimentos históricos e globais de modo interdisciplinar. 
Noutras palavras, a educação ambiental crítica ultrapassa as barreiras sociais, visto que contribui com o processo de emancipação dos sujeitos. Diante deste contexto formativo, dialogar com escolares do ensino fundamental II, fatos contemporâneos e emergentes, pode favorecer na construção de um sujeito, capaz de atuar com responsabilidade no meio sociocultural. Partindo da necessidade da abordagem de uma educação ambiental crítica, capaz de articular diferentes conhecimentos, este artigo busca analisar e discutir um momento dialógico com alunos do sexto ano de uma escola estadual de um município da região noroeste do estado do Rio Grande do Sul, evidenciando a importância das trocas de saberes, vivências e experiências, com vistas a transformar o modo de agir e pensar na sociedade.

\section{Referencial Teórico}

A educação ambiental pode contribuir para libertar os sujeitos das ideias hegemônicas presentes na atualidade. Por este viés, é imprescindível um debate envolvendo as questões sociais, políticas, econômicas, culturais e ambientais, visto que existe uma correlação nestas temáticas. A educação ambiental precisa ir além de uma abordagem conservadora, a qual não relaciona a problemática ambiental com a cultura, a economia, saúde, desigualdades sociais e a política. Layrargues e Lima (2014) destacam que a educação ambiental brasileira, em sua historicidade, apresentou três macrotendências políticopedagógicas, sendo elas: conservadora, pragmática e crítica.

A educação ambiental conservadora, como o próprio nome diz, não supera as ideias hegemônicas e não questiona a relação homem e natureza. A macrotendência pragmática teve suas raízes no estilo de produção pós-guerra e agia como um método de corrigir as imperfeições oriundas do sistema de produção da época. Tanto a conservadora quanto a pragmática não levam em conta as relações sociopolíticas, as desigualdades sociais e os problemas ambientais. Já a macrotendência crítica, também chamada de emancipatória, transformadora ou popular, insere questões voltadas à renovação multidimensional, tendo como base epistemológica as ideias de Paulo Freire, articulando conhecimentos sociais, culturais, políticos, econômicos com as desigualdades sociais e as múltiplas relações com o ambiente, visando auxiliar no processo libertador dos sujeitos (Layrargues \& Lima, 2014).

Pensando na importância de uma educação ambiental crítica, capaz de ultrapassar as barreiras sociais, centrada no diálogo, pode-se dizer que esta macrotendência político-pedagógica instiga um (re)pensar nas questões ambientais, inserindo o homem como agente principal no processo de aceleração da degradação ambiental. Por este viés, não basta apenas pensar no meio ambiente como sendo os rios, o ar, as florestas e os animais. Guimarães (2011) comenta que não podemos restringir o meio ambiente a fauna e a flora, pois esta visão se torna reducionista demais. Devemos pensar em meio ambiente e nas suas múltiplas relações, as quais inserem o homem, suas culturas, as desigualdades sociais, a saúde, a pobreza, bem como a política, a economia e tantas outras temáticas que se relacionam com o meio ambiente.

Na percepção de Silveira e Lorenzetti (2021, p. 13), a educação ambiental crítica “desencadeia na sociedade uma nova forma de agir na natureza, uma vez que os conhecimentos que envolvem a economia, a política, a natureza, a sociedade e o ambiente se tornam pertinentes para um debate constante, tendo possíveis reflexos na sensibilidade humana". Assim, a educação ambiental deve contribuir com a formação crítica, autônoma e reflexiva dos sujeitos, por isso há necessidade da formação de um sujeito ecológico.

O sujeito ecológico agrega uma série de traços, valores e crenças e poderia ser descrito em facetas. Em sua versão política, poderia ser apresentado como um sujeito heroico, vanguarda de um movimento histórico, herdeiro de tradições políticas de esquerda, mas protagonista de novo paradigma político-existencial. Em sua versão Nova Era, é visto como alternativo, integral, equilibrado, harmônico, planetário, holista. Em sua versão de gestor social, supõe-se que partilhe de uma compreensão política e técnica da crise socioambiental, sendo responsável por adotar procedimentos e instrumentos legais para enfrenta-la, por mediar conflitos e planejas ações (Carvalho, 2012, p. 67). 
Na visão de Carvalho (2012), o sujeito ecológico é aquele que adquire habilidades e competências para atuar de forma responsável na sociedade, questionando e fiscalizando as ações de governantes e da sociedade em geral. O sujeito ecológico é aquele que age com autonomia e senso crítico no meio sociocultural, dialogando com os diferentes grupos as questões que correlacionam meio ambiente, cultura, economia, sociedade e política. Ainda, o sujeito ecológico compreende a sua importância na sociedade, haja vista que ele insere na sua prática diária valores e condutas que contribuem não apenas com a preservação ambiental, mas também com boas maneiras de atuar na sociedade, respeitando a pluralidade de saberes, vivências e experiências de outros grupos.

Debater a educação ambiental crítica consiste em criar condições de se tornar um sujeito reflexivo. Na visão de Freire (1967), os sujeitos precisam se libertar das ideias alienadoras provenientes de alguns grupos sociais e a educação precisa ser uma forma de intervenção social, pautando práticas e ações que culminem em transformações socioambientais. Os sujeitos precisam compreender que apresentam direitos e deveres, portanto, devem atuar como líderes na sociedade. Em se tratando da educação ambiental, Leff (2012) destaca que precisa haver uma epistemologia do saber ambiental, instigando o desenvolvimento crítico e reflexivo dos sujeitos para as questões ambientais emergentes. A ação de inúmeros sujeitos pode trazer benefícios as futuras gerações, contribuindo de forma significativa com a formação ética, crítica e emancipatória da sociedade.

A educação ambiental precisa contribuir com a formação identitária dos sujeitos. Para isso ocorrer é imprescindível que os ambientes educacionais promovam atividades que insiram a comunidade escolar nas atividades interdisciplinares de educação ambiental. As atividades devem agrupar fatos e circunstâncias que estão presentes no dia a dia dos alunos, buscando encontrar respostas aos problemas da comunidade. Diante deste contexto, a comunidade acaba compreendendo a importância da escola, bem como das práticas ambientais com vistas a contribuir com uma melhora na vida dos cidadãos. Na visão de Freire (2010), para haver uma educação libertadora, é necessário criar espaços para as discussões, bem como conhecer as vivências dos sujeitos. A educação ambiental crítica permite este diálogo e momentos interativos quando os sujeitos compreendem que fazem parte do meio ambiente e apenas ações de recolher materiais, explanar questões de lixo, poluição e destruição da natureza não irá combater a degradação ambiental. É preciso ir além, é necessário discutir fatos sociais, ambientais, históricos, culturais e políticos, visando mitigar os problemas socioambientais emergentes na contemporaneidade.

\section{Metodologia}

Pensando nas formas de mediar o conhecimento, Pereira et al. (2018, p. 13) afirmam que "O conhecimento pode ser adquirido de diversas formas: sensação, percepção, imaginação, memória, linguagem, raciocínio e intuição". Pensando nisso, este estudo utilizou a abordagem metodológica do tipo qualitativa. Para Minayo (2012), as pesquisas qualitativas são, geralmente, utilizadas nas pesquisas sociais, possibilitando uma abrangência de conhecimentos no tocante da sociedade. Nesse sentido, ocorre a interpretação de fatos presentes no meio social e que apresentam relevância para a contemporaneidade. De acordo com Marconi e Lakatos (2004, p. 269), "a metodologia qualitativa preocupa-se em analisar e interpretar aspectos mais profundos, descrevendo a complexidade do comportamento humano". Nesse mesmo sentido, cabe-se dizer que:

a pesquisa qualitativa envolve o estudo do uso e a coleta de uma variedade de materiais empíricos - estudos de casos; experiência pessoal; introspecção; história de vida; entrevista; artefatos; textos e produções culturais; textos observacionais/registros de campo; históricos interativos e visuais - que descrevem momentos significativos rotineiros e problemáticos na vida dos indivíduos (Denzin; Lincoln, 2006, p. 17).

Buscando compreender os saberes dos alunos acerca das questões ambientais, sociais, políticas, culturais, históricas e econômicas, foi realizado um estudo de caso com alunos do sexto ano de uma escola estadual que se encontra localizada em 
um município da região noroeste do estado do Rio Grande do Sul. Sobre a importância do estudo de caso Yin (2010, p. 23), comenta que "o método do estudo de caso permite que os investigadores retenham as características holísticas e significativas dos eventos da vida real - como os ciclos individuais da vida, do comportamento dos pequenos grupos, os processos organizacionais e administrativos". No mesmo sentido, Gil (2011) afirma que o estudo de caso "Consiste no estudo profundo e exaustivo de um ou poucos objetos, de maneira que permita seu amplo e detalhado conhecimento, tarefa praticamente impossível mediante outros delineamentos já considerados".

Salienta-se que o momento dialógico foi gravado e transcrito. Como forma de análise, optou-se pela Análise Textual Discursiva - ATD. Moraes e Galiazzi (2006) comentam que a Análise Textual Discursiva começa com a unitarização dos dados, em que os textos são divididos em unidades menores. Estas unidades ainda podem ser subdivididas em outras unidades, a partir do olhar empírico do pesquisador.

\section{Resultados e Discussão}

No ambiente educacional deve-se haver constantes debates, provocações e trocas de saberes, visando a construção do conhecimento de forma significativa e que inter-relacione questões históricas, políticas, culturais, sociais, ambientais e econômicas. Nesta perspectiva de debate é que se perfaz uma educação ambiental crítica, sendo capaz de contribuir com o processo formativo humano, crítico e emancipatório dos sujeitos para as vivências em sociedade (Carvalho, 2012).

A atividade dialógica contou com 21 alunos, no turno das aulas normais de ciências e teve a incumbência de instigar o processo reflexivo dos discentes sobre as questões ambientais presentes no dia a dia. Os alunos foram convidados pelo professor-mediador a sentaram-se em círculo, ao redor de uma mesa, onde ficou o aparelho celular que serviu de recurso para a gravação dos áudios visando, posteriormente, a análise dos dados. Esta prática de sentar em círculo e trocar conhecimentos teve o propósito de inserir a epistemologia de Freire (2010), haja vista que o professor precisa instigar o pensar crítico dos alunos, aplicando uma educação libertadora, não favorecendo no uso da educação bancária e memorística que tão pouco contribui com os aprendizados dos educandos.

Durante a realização da atividade, diversos questionamentos proferidos pelo professor-mediador provocaram o debate e a exposição de conhecimentos, sendo muitos destes relatos, vivências e experiências dos alunos. O primeiro questionamento consistiu na problematização sobre o que é a agroecologia, ainda, se já haviam ouvido falar nesta palavra. De forma voluntária e tímida, poucos alunos responderam à pergunta, sendo que dois responderam ser as plantas, dois não sabiam, um achava ser as plantas e animais e outro contribuiu com a palavra ecossistema.

Questionados sobre o que é sustentabilidade, um aluno respondeu ser sustentação, já outro, acrescentou ter relação com as plantas. A partir disso, o professor-mediador provocou o pensar sobre qual a relação dos alunos participantes da pesquisa com o Planeta. Diante desta argumentação, outros alunos começaram a participar e a timidez começou a diminuir. Assim, alguns relataram que a relação é de viver/existir, tem a ver com a colaboração com a vida. Ainda, outros relataram que tem relação com a ecologia, animais, o ato de não poluir as ruas e as matas. Pode-se observar que, dos que dialogaram neste questionamento, apenas uma aluna afirmou não ter nenhuma ideia. Pensando na prática do diálogo dentro de sala de aula sobre o mundo contemporâneo, Carvalho (2012, p. 12) explicita que "o desafio é educar as crianças e os jovens propiciando-lhes um desenvolvimento humano, cultural, científico e tecnológico, de modo que adquiram condições para fazer frente às exigências do mundo contemporâneo".

Conforme os alunos expressavam suas opiniões, vivências e experiências, foram questionados se, em suas residências ou, ainda, na residência de seus parentes e/ou amigos, existiam hortas e, ainda, se haviam, alguma vez, auxiliado no plantio de algo. Foi possível observar que a maioria dos alunos demonstraram interesse em responder e assim, de forma organizada, começaram a expressar seus relatos. Dos 21 participantes, $48 \%$ responderam ter horta na sua própria casa. Sobre a questão de 
ter horta em casa e, enfatizando o questionamento sobre o ato de ajudar, o sujeito 2, quanto a sua participação, relatou que: "Eu, meu pai, minha mãe e meus dois irmãos". Com isso, pode-se observar que as hortas são uma estratégia para obter alimentos considerados saudáveis e ajudar a ter uma alimentação com vegetais.

Pode-se dizer que ter uma horta possibilita mitigar gastos com alimentos. Neste mesmo questionamento, os alunos relataram que, em suas residências, há o plantio de alface, rúcula, milho, morango, tomate, maracujá, laranja, bergamota e, segundo o sujeito 7, em sua residência há o plantio de azevém, que é utilizado na alimentação das galinhas e do cavalo. O professor-mediador questionou os alunos se os mesmos conheciam a notícia do rompimento de algumas barragens de rejeitos de minérios no estado de Minas Gerais nos anos de 2015 e 2019, tentando abarcar conhecimentos ambientais catastróficos, tendo o homem e as ideias capitalistas como possíveis responsáveis pela fatalidade de cunho social, ambiental, cultural e econômica da região. Diante disso, a maioria respondeu conhecer esta informação, entretanto, dois alunos responderam não conhecer e a partir disso, abriu-se o diálogo para a compreensão e esclarecimento de todos.

Os alunos relataram que muitas pessoas, animais e plantas morreram. Ainda, o sujeito 8 acrescentou que, em razão deste fato, os moradores perderam "animais, perderam plantas, perderam a vida". O mesmo sujeito expôs que "muita gente ficou sem abrigo". De maneira geral, observou-se que os alunos demonstraram estar abatidos com a gravidade da situação, mediante exposição dos relatos. Assim, pode-se afirmar que os alunos estavam sensibilizados com as consequências geradas pelo rompimento das barragens de rejeitos no estado de Minas Gerais.

Outra pergunta que o professor-mediador fez aos participantes foi quanto a definição de meio ambiente. Diante desta provocação, surgiram diversas respostas, como por exemplo, são as árvores, florestas, animais, natureza, água, ar, aves. Ainda, para o sujeito 6, meio ambiente é o "ambiente em que vivemos". Diante destas respostas é possível perceber que há uma visão conservadora de meio ambiente. Na visão de Guimarães (2011), não podemos reduzir o meio ambiente aos rios, as florestas e aos animais. Para o autor, o meio ambiente precisa ser visto nas suas múltiplas dimensões, relacionando conhecimentos sociais, ambientais, culturais, históricos, políticos e culturais, portanto, observa-se a necessidade do diálogo com a turma para a (des)construção de saberes, permitindo assim, um novo olhar as questões emergentes na atualidade.

Foi questionado ainda se os alunos ingerem apenas produtos industrializados ou utilizavam vegetais provenientes de alguma horta. Quanto a esta pergunta, a maioria respondeu que, frequentemente, consomem tanto alimentos da horta quanto os provenientes do mercado. Apenas uma pesquisada relatou não ingerir alimentos de origem vegetal. Neste diálogo, um aluno comentou que a horta de sua casa foi construída por sua mãe que fez os canteiros com pneus reutilizados. Com isso, ele acrescentou que sua família está ajudando o meio ambiente, pois estão reutilizando materiais que poderiam estar jogados em qualquer lugar.

Analisando este diálogo pode-se perceber há necessidade de um debate envolvendo a temática ambiental com escolares do ensino fundamental II, visto que se deve inserir, comumente, conhecimentos que relacionam saberes sociais, culturais, ambientais, históricos e que precisam de um debate (Layrargues, 2009). Em relação a percepção de meio ambiente por parte dos alunos, é possível dizer que ainda há uma visão conservadora de meio ambiente, portanto, o professor, sendo um mediador do conhecimento, precisa instigar o pensar crítico e reflexivo dos alunos para que eles possam compreender que o meio ambiente está diretamente ligado as ideias hegemônicas e capitalistas de desenvolvimento e que se relacionam com a macrotendência de uma educação ambiental crítica (Silveira \& Lorenzetti, 2021).

A educação ambiental crítica precisa ser vista como uma importante forma de intervenção social, criticizando as desigualdades sociais, a pobreza, a saúde, bem como a lógica capitalista presente. O processo educativo de um sujeito precisa ir além das disciplinas presentes dentro do ambiente escolar. Abordar a temática ambiental consiste em "reconhecer que, para aprender a problemática ambiental, é necessária uma visão complexa de meio ambiente. Em que a natureza integra uma rede de relações não apenas naturais, mas também sociais e culturais" (Carvalho, 2012, p. 38). 
Esta atividade dialógica permitiu compreender a visão de meio ambiente que os alunos do sexto ano de uma escola do estado do Rio Grande do Sul apresentam. Este momento interativo, traz consigo reflexões sobre a prática docente, bem como o processo formativo dos discentes, uma vez que cada aluno apresenta seus saberes, pautado em vivências e experiências. O professor, dentre suas diversas incumbências, deve instigar o pensar crítico e reflexivo dos alunos, direcionando para as (con)vivências em sociedade. Na visão de Loureiro (2006), por meio de momentos dialógicos é que se deve abordar a educação ambiental crítica, problematizando temáticas sociais, culturais, políticas, econômicas, ambientais no contexto da escola, criando condições para que o aluno se torne um sujeito ativo na sociedade, sendo autônomo, responsável e crítico na sua comunidade, ocasionando em transformações sociais.

\section{Considerações Finais}

A educação ambiental crítica, sendo uma importante forma de intervenção social deve ser abordada nos mais variados espaços da sociedade, contribuindo com o processo formativo, crítico e reflexivo dos sujeitos. O diálogo envolvendo a educação ambiental não deve se restringir apenas aos rios, florestas e animais. Ela precisa promover o debate com os diversos grupos sociais, relacionando fatos históricos, culturais, políticos, econômicos e ambientais, (re)pensando a atuação do homem nos mais diversos segmentos da sociedade.

A educação ambiental deve promover as trocas de saberes e as múltiplas relações entre os sujeitos, embasados por um contexto interdisciplinar e instigando constantes problematizações acerca das especificidades e das situações emergentes na contemporaneidade. Da mesma forma, a educação ambiental, pelo viés crítico - embasado na epistemologia freiriana - precisa centrar no diálogo, questionando ideias e ações hegemônicas, pautadas no capitalismo e nas desigualdades sociais. Quanto maior o debate, maiores serão as probabilidades de mudanças no modo de pensar e agir na sociedade, portanto, a educação ambiental crítica precisa ir além de momentos conservadores e pragmáticos, pois pensar em meio ambiente consiste em pensar nas ações antrópicas e nas suas múltiplas relações.

Esta atividade formativa trouxe consigo reflexões acerca da importância do diálogo dentro do contexto escolar, bem como a relevância de instigar o processo reflexivo dos alunos para as temáticas emergentes, como por exemplo, o meio ambiente. Sugere-se que os professores dos diferentes níveis de ensino despertem em seus alunos um olhar crítico as questões sociais, culturais, econômicas, ambientais, política e históricas, tendo por base momentos dialógicos e interativos, com vistas a construírem novos saberes.

\section{Agradecimentos}

De forma especial agradeço a Fundação de Amparo à Pesquisa do Estado do Rio Grande do Sul - FAPERGS pela bolsa de pesquisa durante o curso de Mestrado Acadêmico em Práticas Socioculturais e Desenvolvimento Social. Externo os agradecimentos a Coordenação de Aperfeiçoamento de Pessoal de Nível Superior - CAPES, pela bolsa de pesquisa no curso de Doutorado em Educação em Ciências e em Matemática da Universidade Federal do Paraná, pois o fomento possibilitou o desenvolvimento e êxito desta pesquisa, bem como a elaboração da escrita do presente artigo.

\section{Referências}

Carvalho, I. C. M. (2012). Educação ambiental: a formação do sujeito ecológico. Cortez.

Denzin, N. K., \& Lincoln, Y. (2006). A disciplina e a pratica da pesquisa qualitativa. In: Denzin, N. K., \& Lincoln, Y (Orgs). Planejamento da pesquisa qualitativa: teorias e abordagens. 2 ed. Porto Alegre: ARTMED.

Freire, P. (1967). Educação como prática da liberdade. Paz e Terra.

Freire, P. (2010). Pedagogia da autonomia: saberes necessários à prática educativa. (41a ed.), Paz e Terra. 
Research, Society and Development, v. 10, n. 3, e37110313558, 2021

(CC BY 4.0) | ISSN 2525-3409 | DOI: http://dx.doi.org/10.33448/rsd-v10i3.13558

Gil, A. C. (2011). Como elaborar projetos de pesquisas. Atlas.

Guimarães, M. (2011). Caminhos da educação ambiental: da forma à ação. Papirus.

Layrargues, P. (2009). Educação ambiental com compromisso social: o desafio da superação das desigualdades. In: Loureiro, C. F. B., Layrargues, L. \& R. Castro, R. (Eds.). Repensar a educação ambiental: um olhar crítico. Cortez.

Layrargues, P., \& Lima, G. (2014). As macrotendências político-pedagógicas da educação ambiental brasileira. Ambiente \& Sociedade, 17 (1), $23-40$.

Leff, E. (2012). Aventuras da epistemologia ambiental: da articulação das ciências ao diálogo de saberes. Cortez.

Loureiro, C. (2006). Educação ambiental e “teorias críticas”. In: Guimarães, M. (Org), Caminhos da educação ambiental: da forma à ação. São Paulo: Papirus.

Marconi, M. de A., \& Lakatos, E. M. (2004). Metodologia científica. Editora Atlas.

Minayo, M. C. de S. (Org.). (2012). Pesquisa social: teoria, método e criatividade. (32a ed.), Vozes. (Coleção Temas Sociais).

Moraes, R., \& Galiazzi, M. (2006). Análise textual discursiva: processo reconstrutivo de múltiplas faces. Ciência \& Educação, 12 (1), 117-128.

Pereira, A. S., Shitsuka, D. M., Parreira, F. J., \& Shitsuka, R. Metodologia da pesquisa científica. UFSM.

Silveira, D. P. da, \& Lorenzetti, L. (2021). Estado da arte sobre a educação ambiental crítica no Encontro Pesquisa em Educação Ambiental. Praxis \& Saber, $12(28), 1-15$.

Yin, R. K. (2010). Estudo de caso: planejamentos e métodos. Bookman. 